\title{
Has the Severity of Rheumatoid Arthritis at Presentation Diminished Over Time?
}

\author{
Janet G. Diffin, Mark Lunt, Tarnya Marshall, Jacqueline R. Chipping, Deborah P.M. Symmons, \\ and Suzanne M.M. Verstappen
}

\begin{abstract}
Objective. To examine the pattern of disease severity in patients with rheumatoid arthritis (RA) at presentation to the Norfolk Arthritis Register (NOAR) over 20 years.

Methods. NOAR is a primary-care-based cohort of patients with recent-onset inflammatory polyarthritis. At baseline, subjects are assessed and examined by a research nurse. The Health Assessment Questionnaire (HAQ) is administered and the DAS28 (28-joint Disease Activity Score) is calculated. Information is collected on disease-modifying antirheumatic drug exposure. In this study, patients (symptom duration of < 2 years at baseline) were grouped into 4 cohorts (Cohort 1: 1990-1994; Cohort 2: 1995-1999; Cohort 3: 2000-2004; Cohort 4: 2005-2008). The American College of Rheumatology/European League Against Rheumatism (ACR/EULAR) 2010 criteria for RA were applied retrospectively at baseline. Regression analyses were used to examine whether calendar year of presentation to NOAR was associated with baseline HAQ and DAS28 scores. Potential confounders included age at symptom onset, sex, rheumatoid factor, and anticyclic citrullinated peptide antibody positivity.

Results. A total of 1724 patients met the ACR/EULAR 2010 RA criteria at baseline. Unadjusted mean DAS28 scores decreased over time. Calendar year of presentation to NOAR was significantly associated with lower DAS28 scores over time $\left[\mathrm{Y}=4.51+(-0.56 \times\right.$ year $)+\left(0.44 \times\right.$ year $\left.\left.^{2}\right)\right]$. Although unadjusted median HAQ scores increased over time, calendar year of presentation to NOAR was not significantly associated with HAQ scores $[\mathrm{Y}=(1.1)+(0.023 \times$ year $)+(0.05 \times$ year $\left.\left.^{2}\right)\right]$. Similar results were observed in each subpopulation of patients.

Conclusion. While baseline disease activity has lessened slightly over time, there has been no improvement in baseline levels of functional disability. (First Release July 1, 2014; J Rheumatology 2014;41:1590-9; doi:10.3899/jrheum.131136)
\end{abstract} Key Indexing Terms:
RHEUMATOID ARTHRITIS
DISEASE SEVERITY

\author{
FUNCTIONAL DISABILITY \\ INCEPTION COHORT
}

\section{DISEASE ACTIVITY CHANGES OVER TIME}

It has been suggested that the disease course of rheumatoid arthritis (RA) is becoming less severe ${ }^{1,2,3,4}$. Indicators of severity include levels of functional disability, disease activity, and joint damage. Changes in the severity of RA over time have been investigated in studies examining longer-term outcomes for patients $5,6,7,8,9,10$. The majority of such studies have reported a decline in the longer-term severity of RA in patients seen in more recent years. Explanations for this decline include earlier diagnosis of RA, the increased and earlier use of disease-modifying antirheumatic drugs (DMARD), more aggressive treatment strategies earlier in the disease course ${ }^{6,7,8,10}$, and a secular
From the Arthritis Research UK Centre for Epidemiology, Manchester Academic Health Science Centre, and The School of Nursing, Midwifery, and Social Work, University of Manchester, Manchester; Department of Rheumatology, Norfolk and Norwich University Hospital, Norwich; Norfolk Arthritis Register (NOAR), School of Medicine, Health Policy, and Practice, University of East Anglia, Norwich; UK National Institute for Health Research (NIHR) Manchester Musculoskeletal Biomedical Research Unit, Central Manchester University Hospitals National Health Service (NHS) Foundation Trust and University of Manchester Partnership, Manchester, UK.

Supported by an unrestricted grant from Glaxo-Smith Kline. NOAR is funded by Arthritis Research UK (grant number 20380).

J.G. Diffin, PhD, Research Associate, Arthritis Research UK Centre for Epidemiology, Manchester Academic Health Science Centre, and The School of Nursing, Midwifery, and Social Work, University of Manchester; M. Lunt, PhD, Reader in Medical Statistics, Arthritis Research UK Centre for Epidemiology, Manchester Academic Health Science Centre,

\begin{abstract}
University of Manchester; T. Marshall, MD, Consultant Rheumatologist, Department of Rheumatology, Norfolk and Norwich University Hospital; J.R. Chipping, NOAR Deputy Clinical Manager, School of Medicine, Health Policy, and Practice, University of East Anglia; D.P.M. Symmons, $M D, F R C P, F F P H$, Arthritis Research UK Centre for Epidemiology, Manchester Academic Health Science Centre, University of Manchester, and NIHR Manchester Musculoskeletal Biomedical Research Unit, Central Manchester University Hospitals NHS Foundation Trust and University of Manchester Partnership; S.M.M. Verstappen, PhD, Senior Research Fellow, Arthritis Research UK Centre for Epidemiology, Manchester Academic Health Science Centre, University of Manchester. Address correspondence to Dr. S. Verstappen, Arthritis Research UK Centre for Epidemiology, Manchester Academic Health Science Centre, University of Manchester, Stopford Building, Oxford Road, Manchester M13 9PT, UK. E-mail: Suzanne.Verstappen@manchester.ac.uk Full Release Article. For details see Reprints/Permissions at jrheum.com Accepted for publication March 26, 2014.
\end{abstract}


decline in the disease burden of $\mathrm{RA}^{9}$. It is now widely accepted that patients should start DMARD as soon as possible and preferably within the first 12 weeks of the disease $^{11,12}$. There has therefore been a decline in the time between a patient's first visit to a rheumatology clinic and the initiation of DMARD treatment ${ }^{13,14}$. However, it is also possible that there has been a change in the natural history of the disease ${ }^{15}$.

It is important for healthcare planners to be informed if the disease burden of RA has declined; the information can help to identify the proportion of patients requiring health services in the future ${ }^{16}$. Studies comparing patients presenting with RA in more recent decades have reported mixed findings. An early UK study that included both new and existing patients with RA attending a rheumatology clinic between 1970 and 1980 reported that the severity of RA as measured by seropositivity, erosions, and nodules had lessened over time ${ }^{17}$. More recently, a Finnish study compared patients diagnosed with RA and DMARD-naive who entered 1 of 3 treatment or outcome studies initiated in 1983-1985 (symptom duration < 24 mos), 1988-1989 (symptom duration < $12 \mathrm{mos}$ ), or 1995-96 (symptom duration $<24$ mos). Baseline erythrocyte sedimentation rate, C-reactive protein (CRP), and duration of morning stiffness decreased significantly over time, whereas swollen joint count, pain score, and Larsen radiographic damage score remained similar ${ }^{8}$. A longitudinal observational study in the United States examined the severity of RA over time in 418 patients with early disease across 3 inception cohorts with disease onset in the 1970s, 1980s, and 1990s. Patients in the more recent decades had fewer tender joints, shorter symptom duration, and were older, but reported higher levels of pain ${ }^{18}$. Conflicting findings were reported in a study in the Netherlands ${ }^{19}$. The authors grouped 525 patients into 4 cohorts depending on the date of inclusion to the study (1985-1990, 1990-1995, 1995-2000, 2000-2005). All patients had a symptom duration of $<12$ months and no prior use of DMARD. Lower levels of disease activity but higher levels of functional disability were observed at baseline in the most recently recruited cohort. A more recent study from the Nijmegen RA cohort reported decreased disease activity, decreased levels of functional disability, and fewer orthopedic surgeries in patients recruited over a 20 -year period $^{20}$.

Overall, the evidence on whether baseline disease severity has decreased over time is inconclusive. Most of the studies that have compared patients in earlier and more recent decades at presentation have used hospital or clinic-based populations ${ }^{9,18}$ with established disease ${ }^{19}$, and/or have included small samples of patients $8,18,19$. To determine whether patients with RA are presenting with milder disease, it may be more informative to focus on a larger sample of patients presenting early in the disease course and before any treatment has started. Further, the
American College of Rheumatology/European League Against Rheumatism (ACR/EULAR) 2010 RA criteria have been shown to identify a greater proportion of patients as having RA when they first present ${ }^{21,22}$. It may therefore be beneficial to apply these criteria retrospectively when assessing the severity of RA over time.

The main aims of our study were to examine the pattern of disease severity in (1) patients who met the ACR/EULAR 2010 RA criteria at presentation to the Norfolk Arthritis Register (NOAR) over 20 years, (2) all patients with inflammatory polyarthritis (IP) in the NOAR registry (total NOAR population), (3) all patients with IP who were referred to NOAR by their general practitioners (GP), and (4) all patients with IP who were DMARD-naive at baseline.

\section{MATERIALS AND METHODS}

NOAR is a primary care-based inception cohort of patients with recentonset IP, registered with a GP in the former Norwich Health Authority, UK. A detailed description of this register has been published ${ }^{11}$. Since 1990, consecutive cases of IP have been reported to NOAR through GP or attendance at hospital rheumatology clinics. The notification criteria are adults over the age of 16 years at symptom onset, and swelling of at least 2 joints that has lasted for at least 4 weeks. Patients are excluded who are later diagnosed with a condition other than undifferentiated IP, RA, or psoriatic arthritis.

At presentation to NOAR, patients are assessed by a research nurse using a structured interview and a clinical examination. This assessment generally occurs within 1 month of referral. Information collected includes the date of symptom onset, 51-joint swollen and tender joint count, and presence of rheumatoid nodules on examination. The British version of the Health Assessment Questionnaire (HAQ) is completed by the patient ${ }^{23}$. Blood is collected, separated, and then stored at $-20^{\circ} \mathrm{C}$ and subsequently tested for rheumatoid factor (RF; by latex method, positive at a titer of $\geq 1: 40$ ), anticyclic citrullinated peptide antibody (anti-CCP; by Axis-Shield Diastat kit, positive at $\geq 5$ units $/ \mathrm{ml}$ ), and CRP (by endpoint immunoturbidimetric agglutination method, in $\mathrm{mg} / \mathrm{l})$. The 3-component 28-joint Disease Activity Score (DAS28) is calculated using the CRP level ${ }^{24}$. Information on DMARD and steroid treatment is also collected. In NOAR, the ACR/EULAR 2010 criteria $^{25}$ for RA can be applied retrospectively to all patients. In the current study these latter criteria were applied regardless of whether the patient had been prescribed DMARD prior to the baseline assessment. Height and weight has been measured since the year 2000, enabling body mass index (BMI) to be calculated $\left(\mathrm{kg} / \mathrm{m}^{2}\right)$ in patients recruited since 2000 .

Patients with a symptom duration of less than 2 years at baseline were included in the present study. While the inclusion criteria for NOAR have not changed over time, the recruitment policy has changed with respect to the number of GP from whom direct referrals are accepted, with fewer GP practices recruiting in more recent years. In addition, more patients are referred by the rheumatologist, suggesting that patients are seen earlier by rheumatologists now compared to 15 years ago. For this reason, the subpopulation of patients with IP referred to NOAR by their GP was analyzed.

Within the current study, consecutively recruited patients were grouped into 4 cohorts depending on the NOAR recruitment phase, enabling a comparison in baseline demographic and disease characteristics over 20 years (Cohort 1: 1990-1994; Cohort 2: 1995-1999; Cohort 3: 2000-2004; Cohort 4: 2005-2008).

Ethical approval was given by the Norfolk and Norwich University Hospital Local Research Ethics Committee. All patients provided written consent.

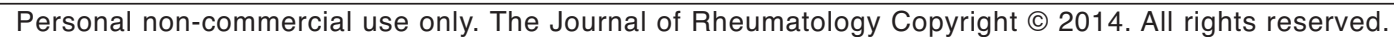


Statistical analyses. Baseline differences in demographic and disease characteristics over time were analyzed using ANOVA for normally distributed continuous variables, Kruskal-Wallis test for non-normally distributed continuous variables, and the chi-square for categorical variables ( $\mathrm{p}<0.05$ were considered statistically significant). The associations between the baseline characteristics, the calendar year of presentation to NOAR, and HAQ and DAS28 scores were examined using a series of regression models. Either baseline HAQ scores or baseline DAS28 scores were included as the dependent variable, and the calendar year of presentation to NOAR as the independent variable. All assumptions were explored prior to the regression analyses. A linear regression model was conducted if the dependent variable was normally distributed, and a median regression model was conducted if the distribution of dependent variable was non-normal. A quadratic term for calendar year was included in the model if the association between the dependent variable and calendar year was curvilinear. Confounders were selected based on the existing literature and the results of the univariate analysis and included sex, RF and/or anti-CCP positivity, and age at symptom onset. If the calendar year of presentation to NOAR emerged as a significant predictor within the regression models, the variable "Cohort" was added to the regression model as a categorical variable (Cohort 1 to 4 ) to examine whether there was a significant difference between each cohort in the outcome variable. A "Calendar year by Cohort" interaction term was included if the results indicated a significant difference in the outcome variable between cohorts A statistically significant interaction term indicates that the rate of change in DAS28 or HAQ scores with calendar year was different within each cohort of patients; and therefore there may be differences in the characteristics of patients within each cohort that may explain any changes observed in the outcome variable, rather than the passage of time. All variables within each regression model were subsequently standardized and the regressions were rerun to obtain the coefficients, enabling a graphic representation of the relationship between the independent and dependent variables.

All analyses were subsequently repeated in each subgroup (Tables 1-4, Appendixes 1-4), including all patients with IP in the NOAR registry (total NOAR population), all patients with IP who were referred to NOAR by their GP, and all patients with IP who were DMARD naïve at baseline. All data analyses were conducted using STATA Version $11^{26}$

\section{RESULTS}

Description of total population. There were 1724 patients who met the ACR/EULAR 2010 RA criteria at baseline (Cohort 1: 1990-1994, 614; Cohort 2: 1995-1999, 456; Cohort 3: 2000-2004, 347; Cohort 4: 2005-2008, 307). The baseline characteristics are presented in Table 1. Of these 1724 patients, 981 (56.9\%) were taking DMARD prior to the baseline assessment [Cohort 1, $20.5 \%$ (126/614); Cohort 2, 37.9\% (173/456); Cohort 3, 56.8\% (197/347); Cohort 4, $56.7 \%(174 / 307)]$. Median age at symptom onset differed significantly between each cohort $(\mathrm{p}=0.02)$ and increased from 56 years [interquartile range (IQR) 44, 68] in Cohort 1 to 59 years (IQR 49,69) in Cohort 3 . The median symptom duration did not differ significantly between each cohort ( $\mathrm{p}=0.07)$ and increased only slightly from 5 months (IQR 3,10 mos) in Cohort 1 to 6 months (IQR 4, 11) in Cohort 4. There was a small increase in the proportion of women (Cohort 1: 65.8\%; Cohort 4: 68.7\%). The proportion of patients who were ex-smokers, current smokers, and who never smoked remained similar over time. Median levels of CRP increased over time [Cohort 1: $8 \mathrm{mg} / \mathrm{l}$ (IQR 1, 22);
Cohort 4: $13.7 \mathrm{mg} / \mathrm{l}(8.2,23.7)]$. The proportion of patients who were anti-CCP-positive and/or RF-positive increased over time from $45.4 \%$ (208/458) in Cohort 1 to $69.2 \%$ $(171 / 247)$ in Cohort 4. BMI was not available for Cohort 1 and 2; however, the proportion of morbidly obese patients increased from 5.6\% (19/336) in Cohort 3 to $11.3 \%(34 / 301)$ in Cohort 4.

Description of subgroups. There were 3045 patients evaluated within the total NOAR IP population (Table 2), and of these patients, 1136 were referred to NOAR by their GP (Table 3); 2064 were DMARD-naive at baseline (Table 4). Similarly to the RA population, the proportion of patients who were anti-CCP-positive and/or RF-positive, and the proportion of patients who had been prescribed DMARD or steroid treatment prior to the baseline assessment, increased over time. The number of patients referred to NOAR directly by their GP (and the number of GP from whom direct referrals are taken) has decreased in more recent years. Within the GP referral subpopulation, the proportion of patients who were current smokers decreased over time, and the proportion of ex-smokers increased, whereas in the other subpopulations the proportion of smokers remained more stable over time.

The relationship between calendar year and DAS28 scores. Unadjusted mean DAS28 scores at baseline decreased between Cohort 1 and Cohort 3, and increased slightly between Cohort 3 and Cohort 4, within all samples of patients assessed. A linear regression model was conducted as the DAS28 scores displayed a normal distribution. As the decrease in DAS28 scores with calendar year was nonlinear in all groups, a quadratic term for calendar year was included in the model. After adjusting for confounders, calendar year of presentation to NOAR was significantly associated with a decrease in DAS28 scores over time for patients who met the ACR/EULAR 2010 RA Criteria [Y = $4.51+(-0.56 \times$ year $)+\left(0.44 \times\right.$ year $\left.\left.^{2}\right)\right]$. Calendar year was also significantly associated with a decrease in DAS28 scores over time for the total IP population $[\mathrm{Y}=3.77+$ $(-0.72 \times$ year $)+\left(0.61 \times\right.$ year $\left.\left.^{2}\right)\right]$, the GP-referred IP population $\left[\mathrm{Y}=(3.67)+(-0.34 \times\right.$ year $)+\left(0.20 \times\right.$ year $\left.\left.^{2}\right)\right]$, and the DMARD-naive IP population $[\mathrm{Y}=3.96+(-1.16 \times$ year $)+\left(1.00 \times\right.$ year $\left.\left.^{2}\right)\right]$. Figure 1 displays the results of the regressions for each population of patients using the standardized values.

To establish whether there were significant differences between cohorts, "Cohort" was added to each regression model. For the patients who met the ACR/EULAR 2010 RA Criteria, and the subpopulation of patients with IP who were DMARD-naive at baseline, there was a significant effect of "Cohort" on DAS28 scores, and the results indicated that patients in later cohorts had lower scores than patients in the earliest cohort. The "Calendar year by Cohort" interaction term was therefore added to the model. The results indicated that the rate of change in DAS28 scores with the calendar

Personal non-commercial use only. The Journal of Rheumatology Copyright @ (2014. All rights reserved. 
Table 1. Baseline demographic and clinical characteristics for the 4 cohorts of patients who met the ACR/EULAR 2010 RA criteria at baseline.

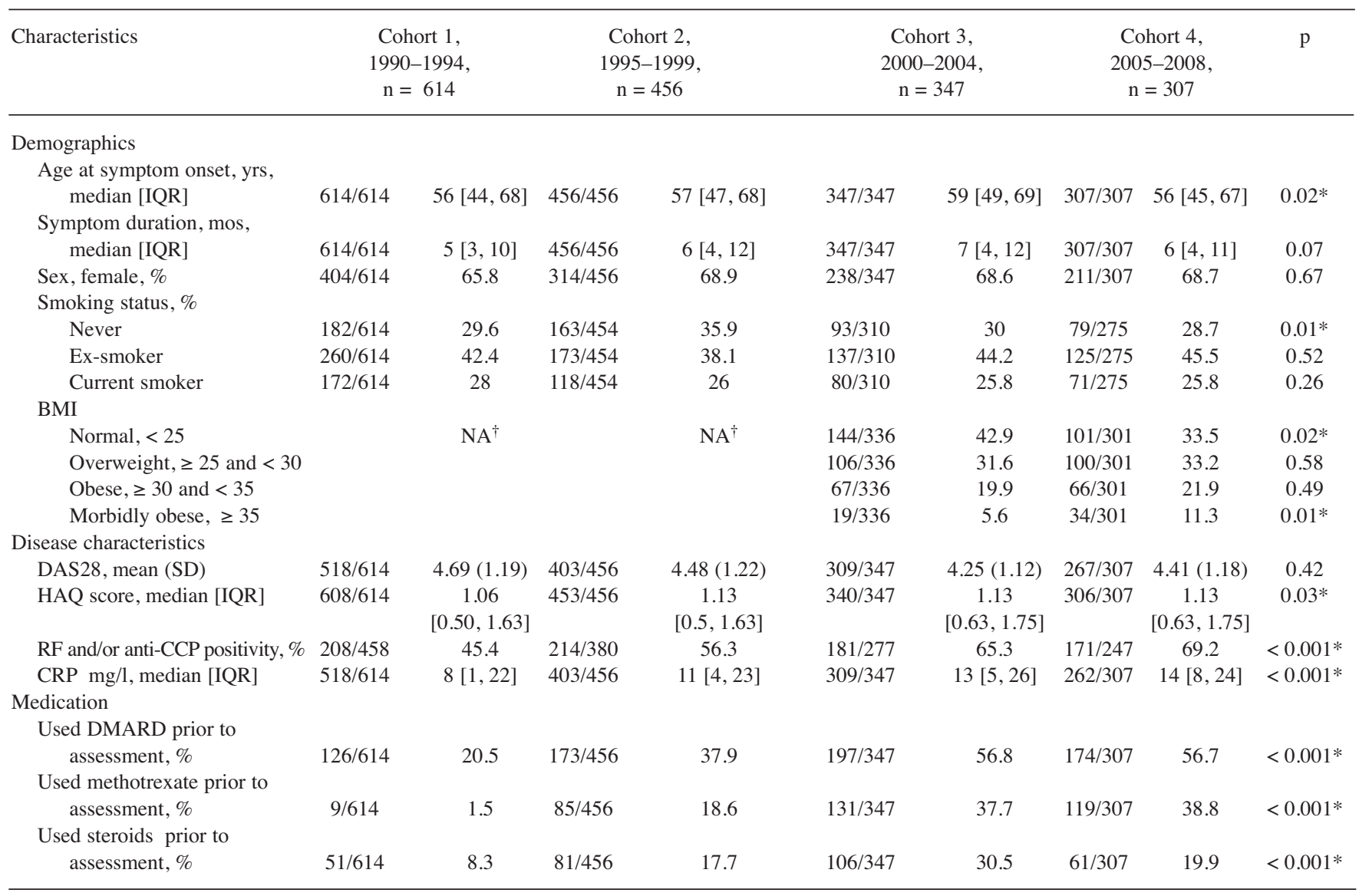

*Statistical significance set at 0.05 . ${ }^{\dagger} \mathrm{NA}$ : Not available because these data were not collected. HAQ: Health Assessment Questionnaire; DAS28: Disease Activity Score; RF: rheumatoid factor; anti-CCP: anticyclic citrullinated peptide antibody; DMARD: disease-modifying antirheumatic drugs; BMI: body mass index; CRP: C-reactive protein; IQR: interquartile range; ACR/EULAR: American College of Rheumatology/European League Against Rheumatism; RA: rheumatoid arthritis.

year of assessment differed significantly between cohorts for patients who met the ACR/EULAR 2010 RA criteria $(\mathrm{p}<0.001)$ at baseline, and the DMARD-naive IP subpopulation $(\mathrm{p}=0.009)$. There was no significant effect of "Cohort" on DAS28 scores for the total IP population, or for the GP-referred IP subpopulation.

The relationship between calendar year and $H A Q$ scores. Unadjusted median baseline HAQ scores increased over time within each population of patients. A median regression model was conducted because the HAQ scores displayed a non-normal distribution. Because the increase in HAQ scores with calendar year was nonlinear within all samples, a quadratic term for calendar year was included in the model. After adjusting for confounders, HAQ scores did increase slightly over time for the patients who met the ACR/EULAR 2010 criteria for RA [Y $=(1.1)+(0.023 \times$ year $)+\left(0.05 \times\right.$ year $\left.\left.^{2}\right)\right]$; however, calendar year was not significantly associated with HAQ scores. Similar results were observed in the total IP population $[\mathrm{Y}=0.80+(0.11 \times$ year $)+\left(-0.087 \times\right.$ year $\left.\left.^{2}\right)\right]$, and the GP-referred IP subpopu- lation $\left[\mathrm{Y}=(0.57)+(0.016 \times\right.$ year $)+\left(0.026 \times\right.$ year $\left.\left.^{2}\right)\right]$, and there was no significant association between calendar year and HAQ scores. For the DMARD-naive IP subpopulation, a decrease in HAQ scores over time was observed [ $\mathrm{Y}=$ $(1.05)+(-0.15 \times$ year $)+(0.094 \times$ year $)]$; however, there was no significant association between calendar year and HAQ scores. No additional analyses were conducted to examine the effect of calendar year on HAQ scores. Figure 2 displays the results of the regressions for each population of patients using the standardized values.

\section{DISCUSSION}

The main objective of our study was to examine the severity of RA and IP at the time of presentation to NOAR over 20 years. Within each population of patients assessed, baseline disease activity lessened over time. While the relationship was nonlinear, scores in the more recent cohorts were lower than those in the earliest cohort. The improvement in disease activity coincided with an increase in the earlier use of DMARD and steroids in the more recent cohorts. The rate

Personal non-commercial use only. The Journal of Rheumatology Copyright (c 2014. All rights reserved. 
Table 2. Baseline demographic and clinical characteristics for the 4 cohorts within the total sample of patients with inflammatory polyarthritis.

\begin{tabular}{|c|c|c|c|c|c|c|c|c|c|}
\hline \multirow{2}{*}{$\begin{array}{l}\text { Characteristics } \\
\text { Demographics }\end{array}$} & \multicolumn{2}{|c|}{$\begin{array}{l}\text { Cohort } 1,1990-1994 \\
\mathrm{n}=1022\end{array}$} & \multicolumn{2}{|c|}{$\begin{array}{l}\text { Cohort 2, 1995-1999, } \\
\qquad \mathrm{n}=883\end{array}$} & \multicolumn{2}{|c|}{$\begin{array}{l}\text { Cohort 3, 2000-2004 } \\
\qquad \mathrm{n}=631\end{array}$} & \multicolumn{2}{|c|}{$\begin{array}{c}\text { Cohort 4, 2005-2008 } \\
\qquad \mathrm{n}=509\end{array}$} & \multirow[t]{2}{*}{$\mathrm{p}$} \\
\hline & & & & & & & & & \\
\hline $\begin{array}{l}\text { Symptom duration, mos, } \\
\text { median }[\mathrm{IQR}]\end{array}$ & $1022 / 1022$ & $5[3,9]$ & $883 / 883$ & $6[4,12]$ & $631 / 631$ & $6[4,11]$ & $509 / 509$ & $6[4,11]$ & $<0.001^{*}$ \\
\hline Never & $323 / 1021$ & 31.6 & $343 / 881$ & 38.9 & $181 / 569$ & 31.8 & $134 / 446$ & 30.0 & $<0.001 *$ \\
\hline Ex-smoker & $424 / 1021$ & 41.5 & $325 / 881$ & 36.9 & $245 / 569$ & 43.1 & $200 / 446$ & 44.8 & 0.221 \\
\hline Current smoker & $274 / 1021$ & 26.8 & $213 / 881$ & 24.2 & $143 / 569$ & 25.1 & $112 / 446$ & 25.1 & 0.118 \\
\hline \multicolumn{10}{|l|}{ BMI } \\
\hline Normal,$<25$ & & $\mathrm{NA}^{\dagger}$ & & $\mathrm{NA}^{\dagger}$ & $257 / 615$ & 41.8 & $160 / 501$ & 31.9 & $0.001 *$ \\
\hline Overweight, $\geq 25$ and $<30$ & & & & & $224 / 615$ & 36.4 & $192 / 501$ & 38.3 & 0.44 \\
\hline HAQ score, median [IQR] & $1010 / 1022$ & $\begin{array}{c}0.75 \\
{[0.25,1.37]}\end{array}$ & $877 / 883$ & $\begin{array}{c}0.75 \\
{[0.25,1.37]}\end{array}$ & $616 / 631$ & $\begin{array}{c}0.80 \\
{[0.38,1.60]}\end{array}$ & $507 / 509$ & $\begin{array}{c}0.88 \\
{[0.38,1.00]}\end{array}$ & $0.003 *$ \\
\hline RF and/or anti-CCP positivity, $\%$ & $234 / 754$ & 31.0 & $251 / 730$ & 34.4 & $225 / 493$ & 45.6 & $202 / 407$ & 49.6 & $<0.001^{*}$ \\
\hline CRP, mg/l, median [IQR] & $817 / 1022$ & $5[0,16]$ & $739 / 883$ & $8[0,19]$ & $521 / 631$ & $9[3,22]$ & $414 / 509$ & $12[7,21]$ & $<0.001 *$ \\
\hline Met 2010 RA criteria, \% & $614 / 1022$ & 60.1 & $456 / 883$ & 51.6 & $347 / 631$ & 55.0 & $307 / 509$ & 60.3 & $<0.001^{*}$ \\
\hline \multicolumn{10}{|l|}{ Medication } \\
\hline $\begin{array}{l}\text { Used DMARD prior to } \\
\text { assessment, } \%\end{array}$ & $158 / 1022$ & 15.5 & $263 / 883$ & 29.8 & $291 / 631$ & 46.1 & $269 / 509$ & 52.9 & $<0.001 *$ \\
\hline $\begin{array}{l}\text { Used methotrexate prior to } \\
\text { assessment, \% }\end{array}$ & $13 / 1022$ & 1.23 & $127 / 883$ & 14.4 & $189 / 631$ & 30.0 & $180 / 509$ & 35.4 & $<0.001^{*}$ \\
\hline $\begin{array}{l}\text { Used steroids prior to } \\
\text { assessment, } \%\end{array}$ & $80 / 1022$ & 7.8 & $145 / 883$ & 16.4 & $176 / 631$ & 27.9 & $113 / 509$ & 22.2 & $<0.001^{*}$ \\
\hline
\end{tabular}

*Statistical significance set at $0.05 .{ }^{\dagger}$ NA: Not available because these data were not collected. HAQ: Health Assessment Questionnaire; DAS28: Disease Activity Score; RF: rheumatoid factor; anti-CCP: anticyclic citrullinated peptide antibody; DMARD: disease-modifying antirheumatic drugs; BMI: body mass index; CRP: C-reactive protein; IQR: interquartile range; RA: rheumatoid arthritis.

of change in disease activity over time differed for the total population of patients with IP, and for the subpopulation of DMARD-naive IP patients, as indicated by the significant "Cohort by Calendar Year" interaction. This finding suggests that the baseline characteristics of patients may have differed between cohorts. Such differences may be attributable to changes in the recruitment strategy from GP with time. As indicated in Table 2, patients referred to NOAR directly by the GP were a milder cohort of patients in comparison to those referred from the hospital clinics, and therefore changes in disease activity over time may have been less pronounced within the more recent cohorts. In contrast to disease activity, levels of functional disability for patients with RA, the total IP population, and the GP-referred IP subpopulation did not lessen over time. While levels of functional disability did decrease slightly over time for the DMARD-naive IP subpopulation, calendar year was not significantly associated with HAQ scores. Other differences in patients presenting to NOAR over time were also evident. Patients in the later cohorts were older at the time of symptom onset, and were more likely to be RF-positive and anti-CCP-positive, in comparison to patients in the earlier cohorts. Lastly, despite a decrease in the prevalence of smoking in the general population in more recent years ${ }^{27}$, the prevalence of smokers and ex-smokers did not change over time for patients with RA, which is consistent with smoking being a major risk factor for the onset of IP.

Similarly to the current study, Finckh, et al ${ }^{18}$ compared patients presenting with RA who were recruited during the 1970s, 1980s, and 1990s and reported that patients in the more recent cohorts were older. However, patients in the later cohorts had shorter symptom duration, a finding not observed in the current study. In another consecutive observational study, Welsing, et $a l^{19}$ reported that symptom duration and age did not change significantly, but as in the current study, decreases in disease activity and an increase in levels of functional disability were observed in patients in the most recent cohort. The findings of the current study conflict with previous studies, which observed an improve- 
Table 3. Baseline demographic and clinical characteristics for the 4 cohorts within the subsample of patients with inflammatory polyarthritis referred by their general practitioner.

\begin{tabular}{|c|c|c|c|c|c|c|c|c|c|}
\hline \multirow{2}{*}{$\begin{array}{l}\text { Characteristics } \\
\text { Demographics }\end{array}$} & \multicolumn{2}{|c|}{$\begin{array}{l}\text { Cohort } 1,1990-1994 \\
n \mathrm{n}=533\end{array}$} & \multicolumn{2}{|c|}{$\begin{array}{l}\text { Cohort 2, 1995-1999, } \\
\qquad \mathrm{n}=367\end{array}$} & \multicolumn{2}{|c|}{$\begin{array}{c}\text { Cohort 3, 2000-2004, } \\
\qquad \mathrm{n}=149\end{array}$} & \multicolumn{2}{|c|}{$\begin{array}{c}\text { Cohort } 4,2005-2008 \\
n=87\end{array}$} & \multirow[t]{2}{*}{$\mathrm{p}$} \\
\hline & & & & & & & & & \\
\hline $\begin{array}{l}\text { Symptom duration (mos), } \\
\text { median }[\mathrm{IQR}]\end{array}$ & $533 / 533$ & $4[2,7]$ & $367 / 367$ & $5[3,9]$ & $149 / 149$ & $6[3,9]$ & $87 / 87$ & $5[2,9]$ & $<0.001 *$ \\
\hline Never & $169 / 532$ & 31.8 & $159 / 366$ & 43.4 & $44 / 137$ & 32.1 & $24 / 80$ & 30.0 & $<0.001 *$ \\
\hline Ex-smoker & $217 / 532$ & 40.8 & $124 / 366$ & 33.9 & $63 / 147$ & 46.0 & $40 / 80$ & 50.0 & $0.06^{*}$ \\
\hline Current smoker & $146 / 532$ & 27.4 & $83 / 366$ & 22.7 & $30 / 137$ & 22.0 & $16 / 80$ & 20.0 & 0.09 \\
\hline \multicolumn{10}{|l|}{ BMI } \\
\hline Normal, $<25$ & & $\mathrm{NA}^{\dagger}$ & & $\mathrm{NA}^{\dagger}$ & $55 / 143$ & 38.4 & $22 / 85$ & 25.9 & 0.07 \\
\hline Overweight, $\geq 25$ and $<30$, & & & & & $60 / 143$ & 42.0 & $33 / 85$ & 38.8 & 0.72 \\
\hline HAQ score, median [IQR] & $530 / 533$ & $\begin{array}{c}0.63 \\
{[0.13,1.13]}\end{array}$ & $366 / 367$ & $\begin{array}{c}0.63 \\
{[0.13,1.13]}\end{array}$ & $143 / 149$ & $\begin{array}{c}0.75 \\
{[0.25,1.25]}\end{array}$ & $87 / 87$ & $\begin{array}{c}0.75 \\
{[0.38,1.25]}\end{array}$ & 0.24 \\
\hline $\mathrm{RF}$ and/or anti-CCP positivity, $\%$ & $112 / 402$ & 27.9 & $89 / 302$ & 29.5 & $43 / 119$ & 36.1 & $35 / 75$ & 46.7 & $0.007 *$ \\
\hline CRP, mg/l, median [IQR] & $429 / 533$ & $4[0,14]$ & $296 / 367$ & $7[0,19]$ & $118 / 149$ & $6[2,19]$ & $75 / 87$ & $12[7,20]$ & $<0.001 *$ \\
\hline Met 2010 RA criteria, \% & $293 / 533$ & 55.0 & $169 / 321$ & 46.1 & $69 / 149$ & 46.3 & $40 / 87$ & 46.0 & $<0.001 *$ \\
\hline \multicolumn{10}{|l|}{ Medication } \\
\hline $\begin{array}{l}\text { Used DMARD prior to } \\
\text { assessment, } \%\end{array}$ & $30 / 533$ & 5.6 & $46 / 367$ & 12.5 & $28 / 149$ & 18.8 & $12 / 87$ & 13.8 & $<0.001 *$ \\
\hline $\begin{array}{l}\text { Used methotrexate prior to } \\
\text { assessment, \% }\end{array}$ & $1 / 533$ & 0.2 & $15 / 367$ & 4.1 & $11 / 149$ & 7.4 & $7 / 87$ & 8.1 & $<0.001 *$ \\
\hline $\begin{array}{l}\text { Used steroids prior to } \\
\text { assessment, } \%\end{array}$ & $19 / 533$ & 3.6 & $29 / 367$ & 7.9 & $25 / 149$ & 16.8 & $12 / 87$ & 13.8 & $<0.001 *$ \\
\hline
\end{tabular}

${ }^{*}$ Statistical significance set at 0.05 level. ${ }^{\dagger}$ NA: Not available because these data were not collected. HAQ: Health Assessment Questionnaire; DAS28: Disease Activity Score; RF: rheumatoid factor; anti-CCP: anticyclic citrullinated peptide antibody; DMARD: disease-modifying antirheumatic drugs; IQR: interquartile range; BMI: body mass index; CRP: C-reactive protein; RA: rheumatoid arthritis

ment in baseline functional measures for patients seen in more recent years ${ }^{19,20}$. However, patients within these studies had more established disease in comparison to the current study.

Possible explanations for the decreased disease activity of RA over time within the current study include earlier referral to a rheumatologist and an earlier diagnosis of RA. The median delay from symptom onset to first rheumatology visit is estimated to be 23 weeks in the $\mathrm{UK}^{28}$ (i.e., similar to the current study). Symptom duration at NOAR baseline assessment for patients with RA was similar between cohorts, although a greater proportion of patients in the later cohorts were referred from the hospital (i.e., incorporating any delay from GP referral to hospital attendance). Patients referred directly by the GP are a cohort with milder conditions. Thus, there may have been a shorter time between symptom onset and the initiation of DMARD treatment, with more aggressive treatment strategies being prescribed earlier in the disease course. Indeed, the proportion of patients who had been prescribed DMARD treatment prior to the baseline assessment increased over time from $15.5 \%(158 / 1022)$ in Cohort 1 to $52.9 \%$ $(269 / 509)$ in Cohort 4 . The proportion of patients who were prescribed steroids also increased over time from $8.3 \%$ (51/614) in Cohort 1 to 19.9\% (61/307) in Cohort 2.

The benefits of early referral and treatment early in the disease course have been well documented ${ }^{29}$. The more intensive use of available drugs may also help explain the findings ${ }^{30}$. However, it is difficult to determine exactly how much of the improvement in baseline disease activity is attributable to earlier and more aggressive therapy. Even within the DMARD-naive group, the influence of an early treatment strategy may be seen remotely in that this subsample represents those patients whose disease was deemed by the GP or rheumatologist to be milder, and therefore less in need of early therapy. To learn whether results reflected a steroid effect, the same analyses were performed with the sample of patients who were DMARD-naive at baseline, and who had not had steroids prior to the baseline assessment, and similar results were

Personal non-commercial use only. The Journal of Rheumatology Copyright $\subset$ 2014. All rights reserved. 
Table 4. Baseline demographic and clinical characteristics for the 4 cohorts within the subsample of patients with inflammatory polyarthritis who were DMARD-naive at baseline.

\begin{tabular}{|c|c|c|c|c|c|c|c|c|c|}
\hline $\begin{array}{l}\text { Characteristics } \\
\text { Demographics }\end{array}$ & \multicolumn{2}{|c|}{$\begin{array}{c}\text { Cohort } 1,1990-1994 \\
\mathrm{n}=864\end{array}$} & \multicolumn{2}{|c|}{$\begin{array}{c}\text { Cohort 2, 1995-1999, } \\
\mathrm{n}=620\end{array}$} & \multicolumn{2}{|c|}{$\begin{array}{c}\text { Cohort 3, 2000-2004, } \\
\qquad \mathrm{n}=340\end{array}$} & \multicolumn{2}{|c|}{$\begin{array}{c}\text { Cohort 4, 2005-2008, } \\
\qquad \mathrm{n}=240\end{array}$} & $\mathrm{p}$ \\
\hline $\begin{array}{l}\text { Symptom duration, mos, } \\
\text { median }[\mathrm{IQR}]\end{array}$ & $864 / 864$ & $5[3,9]$ & $620 / 620$ & $6[3,12]$ & $340 / 340$ & $6[3,11]$ & $240 / 240$ & $5[3,9]$ & $<0.001^{*}$ \\
\hline Never & $271 / 863$ & 31.4 & $256 / 619$ & 41.4 & $105 / 311$ & 33.8 & $71 / 208$ & 34.1 & $<0.001^{*}$ \\
\hline Ex-smoker & $365 / 863$ & 42.3 & $218 / 619$ & 35.2 & $130 / 311$ & 41.8 & $87 / 208$ & 41.8 & $0.04 *$ \\
\hline Current smoker & $227 / 863$ & 26.3 & $145 / 619$ & 23.4 & $76 / 311$ & 24.4 & $50 / 208$ & 24.0 & 0.22 \\
\hline \multicolumn{10}{|l|}{ BMI } \\
\hline Normal, $<25$ & & $\mathrm{NA}^{\dagger}$ & & $\mathrm{NA}^{\dagger}$ & $133 / 329$ & 40.4 & $71 / 237$ & 30.0 & $0.02 *$ \\
\hline Overweight, $\geq 25$ and $<30$ & & & & & $124 / 329$ & 37.7 & $94 / 237$ & 39.6 & 0.51 \\
\hline HAQ score, median [IQR] & $854 / 864$ & $\begin{array}{c}0.63 \\
{[0.25,1.38]}\end{array}$ & $618 / 620$ & $\begin{array}{c}0.63 \\
{[0.13,1.25]}\end{array}$ & $330 / 340$ & $\begin{array}{c}0.75 \\
{[0.25,1.38]}\end{array}$ & $239 / 240$ & $\begin{array}{c}0.75 \\
{[0.25,1.38]}\end{array}$ & 0.12 \\
\hline $\mathrm{RF}$ and/or anti-CCP positivity, $\%$ & $170 / 641$ & 26.5 & $149 / 509$ & 29.3 & $96 / 264$ & 36.4 & $88 / 193$ & 45.6 & $<0.001^{*}$ \\
\hline CRP, mg/l, median [IQR] & $686 / 864$ & $4[0,14]$ & $501 / 864$ & $7[0,17]$ & $268 / 340$ & $7[3,17]$ & $191 / 240$ & $12[7,21]$ & $<0.001^{*}$ \\
\hline Met 2010 RA criteria, \% & $488 / 864$ & 56.5 & $283 / 620$ & 45.7 & $150 / 340$ & 44.1 & $100 / 240$ & 55.4 & $<0.001^{*}$ \\
\hline \multicolumn{10}{|l|}{ Medication } \\
\hline $\begin{array}{l}\text { Used steroids prior to } \\
\text { assessment, \% }\end{array}$ & $61 / 864$ & 7.1 & $88 / 620$ & 14.2 & $25 / 340$ & 22.1 & $39 / 240$ & 16.3 & $<0.001^{*}$ \\
\hline
\end{tabular}

*Statistical significance set at 0.05 level. ${ }^{\dagger} \mathrm{NA}$ : Not available because these data were not collected. HAQ: Health Assessment Questionnaire; DAS28: Disease Activity Score; RF: rheumatoid factor; anti-CCP: anticyclic citrullinated peptide antibody; DMARD: disease-modifying antirheumatic drugs; IQR: interquartile range; BMI: body mass index; CRP: C-reactive protein; RA: rheumatoid arthritis.

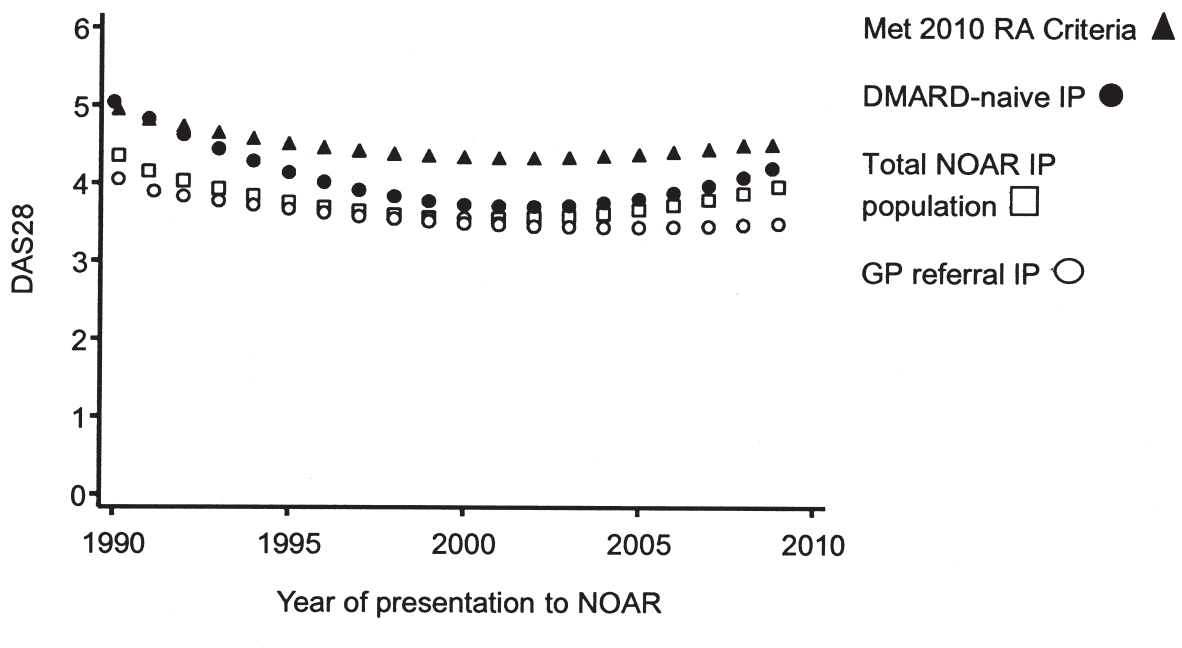

Figure 1. Polynomial regression of DAS28 scores onto calendar year of presentation to NOAR. DAS28: 28-joint Disease Activity Score; NOAR: Norfolk Arthritis Register; RA: rheumatoid arthritis; DMARD: disease-modifying antirheumatic drug; IP: inflammatory polyarthritis; GP: general practitioner.

found (data not shown). Lastly, the improvement in disease activity over time was small, and while this was statistically significant, it would be interesting to understand how clinically meaningful such an improvement is for patients.
However, while there is a recognized minimum clinical important difference (MCID) for HAQ scores, there is no recognized MCID for DAS28 scores.

One explanation why decreased disease activity is not Personal non-commercial use only. The Journal of Rheumatology Copyright @ 2014. All rights reserved. 


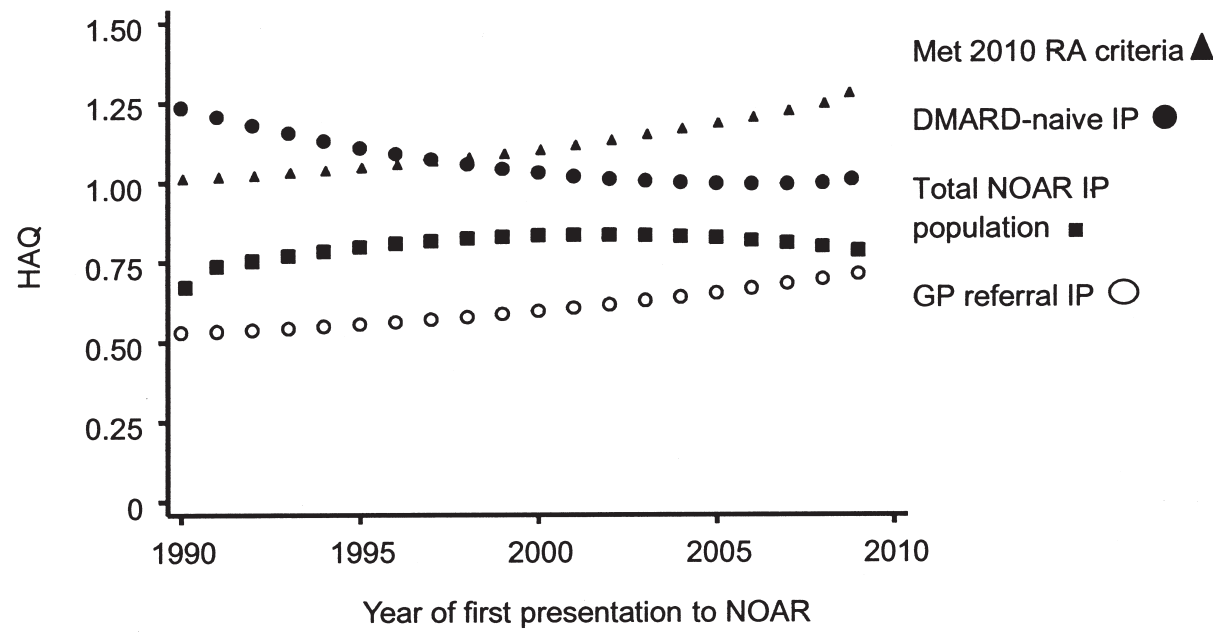

Figure 2. Polynomial regression of HAQ scores onto calendar year of presentation to NOAR. HAQ: Health Assessment Questionnaire; NOAR: Norfolk Arthritis Register; RA: rheumatoid arthritis; DMARD: disease-modifying antirheumatic drug; IP: inflammatory polyarthritis; GP: general practitioner.

reflected in lower levels of functional disability is that functional disability was assessed by a patient-reported outcome measure. In more recent years, patients may have higher expectations when considering their health or be less able to adapt quickly to disability, which may have influenced their response. The concept of disability is multifaceted and is formed by bringing together illness, external support, risk factors, the need for lifestyle changes, psychosocial attributes and coping, and the environment $^{31,32}$. In the general population, a trend of decreased disability/general health has been observed ${ }^{33,34}$. However, this trend was mainly seen in adults aged $>70$ years, which some argue is due to older people having fewer comorbidities in more recent times. Overall, it seems that improvement in disease activity, and possibly fewer comorbidities, do not fully explain why no change in functional disability was observed. Another possible explanation is the link between morbid obesity $(\mathrm{BMI} \geq 35)$ and functional disability in patients with $\mathrm{IP}^{35}$. Unfortunately, BMI was only measured in the last 2 cohorts. Patients in the most recent cohort were more likely to be morbidly obese than those in the cohort before. In addition, the calculation of the HAQ score includes an adjustment for use of aids and devices. People who have help or use a device get a higher score. It is possible that more patients in the later cohort used aids or devices and therefore had higher HAQ scores. Therefore, a sensitivity analysis using the 20-item HAQ scoring method (without adjustment for aids and devices) ${ }^{36}$ was carried out (data not shown). Similar results were observed. Lastly, while HAQ scores improved for patients in the DMARD-naive IP subpopulation, calendar year was not significantly associated with HAQ scores.

Strengths of our study include controlling for the effect of potential confounders such as age at symptom onset, RF positivity, anti-CCP positivity, and sex, and the comparison of disease severity over time in patients presenting early in the disease course. Previous studies have been confined to hospital-based or clinic-based populations and/or only included patients with more established disease ${ }^{21}$. Such studies therefore have the potential for left-censorship. This study reports on a large sample of patients in comparison to previous studies which ranged from a total of 197 to 525 patients ${ }^{8,18,19}$. Our study was able to apply the 2010 criteria for RA retrospectively to patients because all the relevant information was collected at baseline. Lastly, Norfolk has a very stable population and a mix of both rural and urban areas, and there is a central referral system for patients with musculoskeletal symptoms to one secondary care provider. Additionally, a significant effort was made to ensure that all patients with IP newly presenting to primary care were reported to NOAR, including regular visits to GP practices. One potential limitation of our study was the inability to adjust for the effect that comorbidities may have had on results, because of differences in how this information was captured across each cohort over time.

The results of our study demonstrate that there have been some improvements in disease activity as assessed by clinical measures at the time of recruitment into NOAR. This may be partly due to earlier and more aggressive treatment regimes. However, levels of functional disability, as assessed by a patient-reported outcome measure, have not lessened over time.

\section{ACKNOWLEDGMENT}

The authors gratefully acknowledge the support of clinical staff at the Norfolk and Norwich University Hospital, local primary care physicians, and the Norfolk Arthritis Register research nurses. Data management by the team in Manchester is also appreciated.

$$
\text { Personal non-commercial use only. The Journal of Rheumatology Copyright @ } \text { 2014. All rights reserved. }
$$




\section{REFERENCES}

1. Silman AJ. Trends in the incidence and severity of rheumatoid arthritis. J Rheumatology Suppl 1992;32:71-3.

2. Silman AJ. The changing face of rheumatoid arthritis: why the decline in incidence? Arthritis Rheum 2002;46:579-81.

3. Doran MF, Pond GR, Crowson CS, O'Fallon WM, Gabriel SE. Trends in incidence and mortality in rheumatoid arthritis in Rochester, Minnesota, over a forty-year period. Arthritis Rheum 2002;46:625-31.

4. Kaipiainen-Seppänen O, Kutiainen H. Declining trend in the incidence of rheumatoid factor-positive rheumatoid arthritis in Finland 1980-2000. J Rheumatol 2006;33:2132-8.

5. Gordon P, West J, Jones H, Gibson T. A 10 year prospective follow-up of patients with rheumatoid arthritis 1986-96. J Rheumatol 2001;28:2409-15.

6. Krishnan E, Fries JF. Reduction in long-term functional disability in rheumatoid arthritis from 1977 to 1998: a longitudinal study of 3035 patients. Am J Med 2003;115:371-6.

7. Da Silva E, Doran MF, Crowson CS, O'Fallon WM, Matteson EL. Declining use of orthopedic surgery in patients with rheumatoid arthritis? Results of a long-term, population-based assessment. Arthritis Care Res 2003;49:216-20.

8. Sokka T, Kautiainen H, Hakkinen A, Hannonen P. Radiographic progression is getting milder in patients with early rheumatoid arthritis. Results of 3 cohorts over 5 years. J Rheumatol 2004;31:1073-82.

9. Odegard S, Kvien TK, Uhlig T. Incidence of clinically important 10-year health status and disease activity levels in population-based cohorts with rheumatoid arthritis. J Rheumatol 2008;35:54-60.

10. Pincus T, Sokka T, Kautiainen H. Patients seen for standard rheumatoid arthritis care have significantly better articular, radiographic, laboratory, and functional status in 2000 than in 1985. Arthritis Rheum 2005;52:1109-19.

11. Symmons DP, Barrett EM, Bankhead CR, Scott DG, Silman AJ. The incidence of rheumatoid arthritis in the United Kingdom: results from the Norfolk Arthritis Register. Br J Rheumatol 1994;33:735-9.

12. van der Linden MP, le Cessie S, Raza K, van der Woude D, Knevel $\mathrm{R}$, Huizinga TW, et al. Long-term impact of delay in assessment of patients with early arthritis. Arthritis Rheum 2010;62:3537-46.

13. Irvine S, Munro R, Porter D. Early referral, diagnosis, and treatment of rheumatoid arthritis: evidence for changing medical practice. Ann Rheum Dis 1999;58:510-3.

14. Klarenbeek NB, Kerstens PJ, Huizinga TW, Dijkmans BA, Allaart CF. Recent advances in the management of rheumatoid arthritis. BMJ 2010;341:c6942.

15. Walij S, Bykerk VP. Rheumatoid arthritis: is the disease becoming milder or is treatment improving? J Rheumatol 2004;31:1023-5.

16. Uhlig T, Kvien TK. Is rheumatoid arthritis disappearing? Ann Rheum Dis 2005;64:7-10.

17. Silman A, Davies P, Currey HL, Evans SJ. Is rheumatoid arthritis becoming less severe? J Chronic Dis 1983;36:891-7.

18. Finckh A, Choi HK, Wolfe F. Progression of radiographic joint damage in different eras: trends towards milder disease in rheumatoid arthritis are attributable to improved treatment. Ann Rheum Dis 2006;65:1192-7.

19. Welsing PM, Fransen J, van Riel PL. Is the disease course of rheumatoid arthritis becoming milder? Time trends since 1985 in an inception cohort of early rheumatoid arthritis. Arthritis Rheum 2005;52:2616-24.

20. Kievit W, Fransen J, de Waal Malefijt MC, den Broeder AA, van Riel PL. Treatment change and improved outcomes in RA: an overview of a large inception cohort from 1989 to 2009.

Rheumatology 2013;52:1500-8.

21. van der Linden MP, Knevel R, Huizinga TW, van der Helm-van Mil AH. Classification of rheumatoid arthritis: comparison of the 1987 American College of Rheumatology criteria and the 2010 American College of Rheumatology/European League Against Rheumatism criteria. Arthritis Rheum 2011;63:37-42.

22. Humphreys JH, Verstappen SM, Hyrich KL, Chipping JR, Marshall $\mathrm{T}$, Symmons DP. The incidence of rheumatoid arthritis in the UK: comparisons using the 2010 ACR/EULAR classification criteria and the 1987 ACR classification criteria. Results from the Norfolk Arthritis Register. Ann Rheum Dis 2013;72:1315-20.

23. Kirwan JR, Reeback JS. Stanford Health Assessment Questionnaire modified to assess disability in British patients with rheumatoid arthritis. Br J Rheumatol 1986;25:206-9.

24. Fransen J, Welsing PM, de Keijzer RM, van Riel PL. Disease activity scores using C-reactive protein: CRP may replace ESR in the assessment of RA disease activity. Ann Rheum Dis 2003;62 Suppl 1:151.

25. Aletaha D, Neogi T, Silman AJ, Funovits J, Felson DT, Bingham CO 3rd, et al. 2010 Rheumatoid arthritis classification criteria: an American College of Rheumatology/European League Against Rheumatism collaborative initiative. Arthritis Rheum 2010;62:2569-81.

26. StataCorp. Stata Statistical Software: Release 11. College Station, Texas: StataCorp LP; 2009.

27. Simpson CR, Hippisley-Cox J, Sheikh A. Trends in the epidemiology of smoking recorded in UK general practice. Br J Gen Pract 2010;60:e121-7.

28. Kumar K, Daley E, Carruthers DM, Situnayake D, Gordon C, Grindulis K, et al. Delay in presentation to primary care physicians is the main reason why patients with rheumatoid arthritis are seen late by rheumatologists. Rheumatology 2007;46:1438-40.

29. Nell VP, Machold KP, Eberl G, Stamm TA, Uffmann M, Smolen JS. Benefit of very early referral and very early therapy with disease-modifying anti-rheumatic drugs in patients with early rheumatoid arthritis. Rheumatology 2004;43:906-14.

30. González-Alvaro I, Descalzo MA, Carmona L; Estudio de le Morbilidad y Expresión Clínica de la Artritis Reumatoide Study Group. Trends towards an improved disease state in rheumatoid arthritis over time: influence of new therapies and changes in management approach: analysis of the EMECAR cohort. Arthritis Res Ther 2008;10:R138.

31. White C. Update on the harmonisation of disability data collection in UK surveys (Part 1). Health Stat 2011;51:3-30.

32. Verbrugge LM, Jette AM. The disablement process. Soc Sci Med 1994;38:1-14.

33. Freedman VA, Martin LG, Schoeni RF. Recent trends in disability and functioning among older adults in the United States. JAMA 2002;288:3137-46.

34. Martin LG, Schoeni RF, Freedman VA, Andreski P. Feeling better? Trends in general health status. J Gerontol B Psychol Sci Soc Sci 2007;62:S11-21

35. Humphreys JH, Verstappen SM, Mirjafari H, Bunn D, Lunt M, Bruce IN, et al. Association of morbid obesity with disability in early inflammatory polyarthritis: results from the Norfolk Arthritis Register. Arthritis Care Res 2013;65:122-6.

36. Wolfe F. Which HAQ is best? A comparison of the HAQ, MHAQ and RA-HAQ, a difficult 8 item HAQ (DHAQ), and a rescored 20 item HAQ (HAQ20): analyses in 2,491 rheumatoid arthritis patients following leflunomide initiation. J Rheumatol 2001;28:982-9. 
APPENDIX 1. Swollen and tender joint counts for the 4 cohorts within the total sample of patients with inflammatory polyarthritis.

\begin{tabular}{|c|c|c|c|c|c|c|c|c|c|}
\hline \multirow[b]{2}{*}{ Swollen joints, 28, median [IQR] } & \multicolumn{2}{|c|}{$\begin{array}{c}\text { Cohort } 1,1990-1994 \\
\mathrm{n}=1022\end{array}$} & \multicolumn{2}{|c|}{$\begin{array}{c}\text { Cohort 2, 1995-1999, } \\
\qquad \mathrm{n}=883\end{array}$} & \multicolumn{2}{|c|}{$\begin{array}{c}\text { Cohort 3, 2000-2004, } \\
\qquad \mathrm{n}=631\end{array}$} & \multicolumn{2}{|c|}{$\begin{array}{c}\text { Cohort 4, 2005-2008, } \\
\qquad \mathrm{n}=509\end{array}$} & \multirow{2}{*}{$\begin{array}{c}\mathrm{p}^{*} \\
<0.001\end{array}$} \\
\hline & $1022 / 1022$ & $5[1,11]$ & $883 / 883$ & $2[0,8]$ & $631 / 631$ & $2[0,6]$ & $509 / 509$ & $3[0,6]$ & \\
\hline Swollen and tender, 28, median [IQR] & $1022 / 1022$ & $2[0,7]$ & $883 / 883$ & $1[0,4]$ & $631 / 631$ & $0[0,3]$ & $509 / 509$ & $1[0,4]$ & $<0.001$ \\
\hline
\end{tabular}

* Statistical significance set at 0.05 level. IQR: interquartile range.

APPENDIX 2. Swollen and tender joint counts for the 4 cohorts within the subsample of patients with inflammatory polyarthritis who were referred by their general practitioner.

\begin{tabular}{|c|c|c|c|c|c|c|c|c|c|}
\hline \multirow[b]{2}{*}{ Swollen joints, 28, median [IQR] } & \multicolumn{2}{|c|}{$\begin{array}{c}\text { Cohort } 1,1990-1994, \\
\mathrm{n}=533\end{array}$} & \multicolumn{2}{|c|}{$\begin{array}{c}\text { Cohort 2, 1995-1999, } \\
\qquad \mathrm{n}=367\end{array}$} & \multicolumn{2}{|c|}{$\begin{array}{c}\text { Cohort 3, 2000-2004, } \\
\mathrm{n}=149\end{array}$} & \multicolumn{2}{|c|}{$\begin{array}{c}\text { Cohort 4, 2005-2008, } \\
n=87\end{array}$} & \multirow{2}{*}{$\begin{array}{c}\mathrm{p}^{*} \\
<0.001^{*}\end{array}$} \\
\hline & $533 / 533$ & $4[1,10]$ & $367 / 367$ & $2[0,8]$ & $149 / 149$ & $2[0,5]$ & $87 / 87$ & $2[0,4]$ & \\
\hline Swollen and tender, 28, median [IQR] & $533 / 533$ & $2[0,6]$ & $367 / 367$ & $1[0,4]$ & $149 / 149$ & $0[0,2]$ & $87 / 87$ & $0[0,2]$ & $<0.001 *$ \\
\hline
\end{tabular}

*Statistical significance set at 0.05 level. IQR: interquartile range.

APPENDIX 3. Swollen and tender joint counts for the 4 cohorts within the subsample of patients with inflammatory polyarthritis who were DMARD-naive at baseline.

\begin{tabular}{|c|c|c|c|c|c|c|c|c|c|}
\hline \multirow[b]{2}{*}{ Swollen joints, 28, median [IQR] } & \multicolumn{2}{|c|}{$\begin{array}{c}\text { Cohort } 1,1990-1994 \\
n=864\end{array}$} & \multicolumn{2}{|c|}{$\begin{array}{c}\text { Cohort 2, 1995-1999, } \\
\qquad \mathrm{n}=620\end{array}$} & \multicolumn{2}{|c|}{$\begin{array}{c}\text { Cohort 3, 2000-2004, } \\
\qquad \mathrm{n}=340\end{array}$} & \multicolumn{2}{|c|}{$\begin{array}{c}\text { Cohort 4, 2005-2008, } \\
\mathrm{n}=240\end{array}$} & \multirow{2}{*}{$\begin{array}{c}\mathrm{p}^{*} \\
<0.001\end{array}$} \\
\hline & $864 / 864$ & $4[1,10]$ & $620 / 620$ & $2[0,7]$ & $340 / 340$ & $2[0,5]$ & $240 / 240$ & $2[0,6]$ & \\
\hline Swollen and tender, 28, median [IQR] & $864 / 864$ & $2[0,6]$ & $620 / 620$ & $1[0,3]$ & $340 / 340$ & $0[0,2]$ & $240 / 240$ & $0[0,3]$ & $<0.001$ \\
\hline
\end{tabular}

*Statistical significance set at 0.05 level. DMARD: disease-modifying antirheumatic drug; IQR: interquartile range.

APPENDIX 4. Swollen and tender joint counts for the 4 cohorts of patients who met the ACR/EULAR 2010 RA criteria at baseline.

\begin{tabular}{|c|c|c|c|c|c|c|c|c|c|}
\hline Tender joints, 28, median [IQR] & $614 / 614$ & $10[4,16]$ & $456 / 456$ & $8[3,15]$ & $347 / 347$ & $6[2,14]$ & $307 / 307$ & $7[2,13]$ & $<0.001$ \\
\hline Swollen and tender, 28, median [IQR] & $614 / 614$ & $5[1,10]$ & $456 / 456$ & $3[0,8]$ & $347 / 347$ & $2[0,5]$ & $307 / 307$ & $2[0,5]$ & $<0.001$ \\
\hline
\end{tabular}

*Statistical significance set at 0.05 level. ACR: American College of Rheumatology; EULAR: European League Against Rheumatism; RA: rheumatoid arthritis; IQR: interquartile range. 